\title{
TURISMO DE SEGUNDA RESIDENCIA ¿JARDÍN DE LA CIUDAD Ó CIUDAD JARDÍN?
}

\section{El caso de Silvania Cundinamarca*}

Jorge Ariel Moreno Plazas***

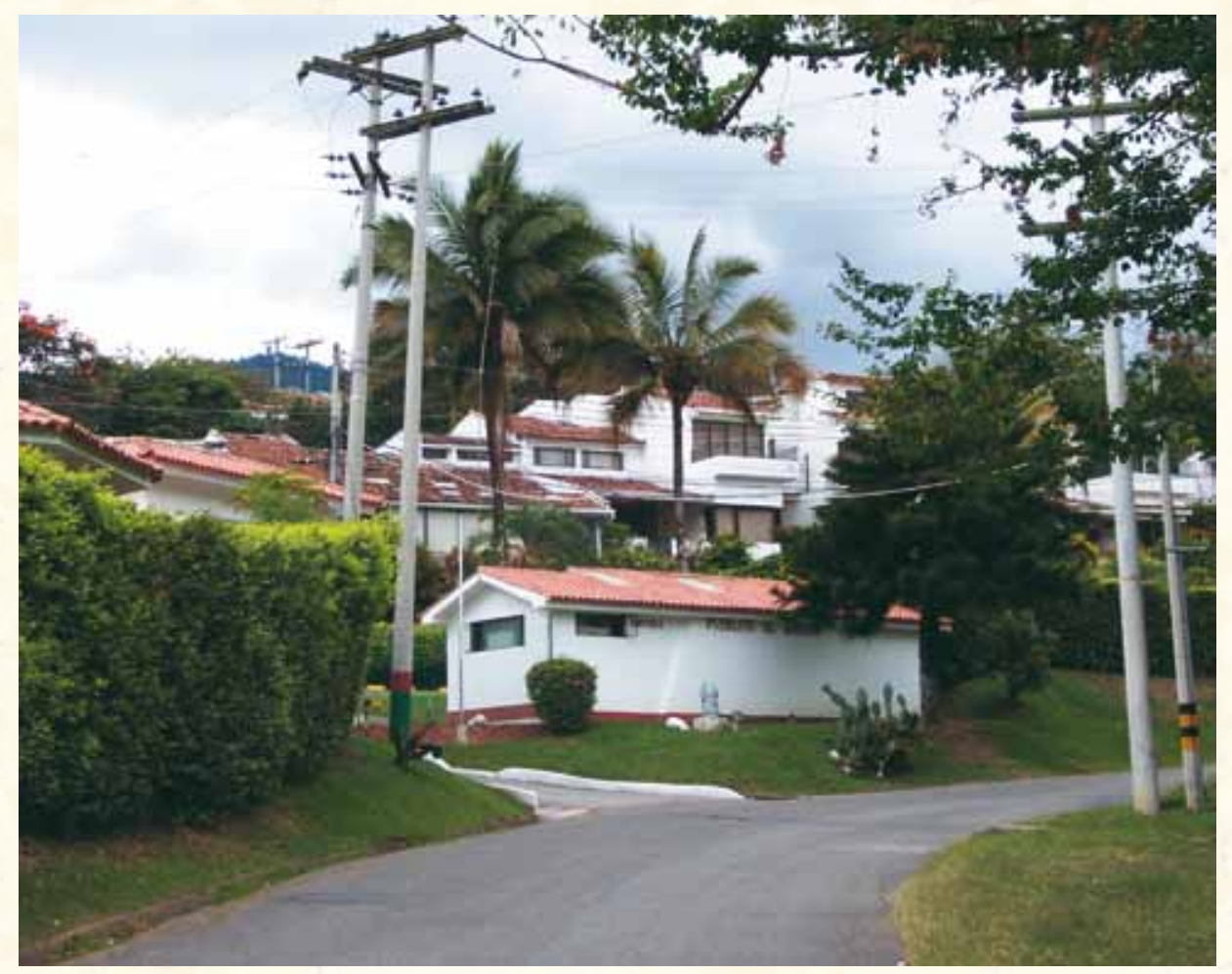

\section{RESUMEN}

Este artículo parte del proyecto de investigación "Distribución y Percepción del Turismo de Segunda Residencia. El Caso de Silvania Cundinamarca", presentado para optar al título de geógrafo de la Universidad Nacional, seccional Bogotá.

Las características locacionales del municipio de Silvania han favorecido el desarrollo del turismo de segunda residencia, estableciéndose como parte de la dinámica de crecimiento de Bogotá, en donde posterior a un proceso de peri-urbanización, se llega bajo la lógica capitalista a formas de sub-urbanización. Esta, a su vez, gradualmente desvirtúa este tipo de turismo por la pérdida en la calidad ambiental inicial y se constituye, entonces, un escenario de especulación inmobiliaria que reta el ordenamiento territorial municipal. Para ilustrar lo anterior se desarrollan los siguientes contenidos: antecedente histórico, elementos conceptuales y ordenamiento territorial con referencia en Silvania.

\section{PALABRAS CLAVE}

Segunda Residencia, sub-urbanización. 


\section{SECOND RESIDENCE TURISM ¿A CITY'S GARDEN OR A GARDEN CITY ?}

\section{Silvania, Cundinamarca}

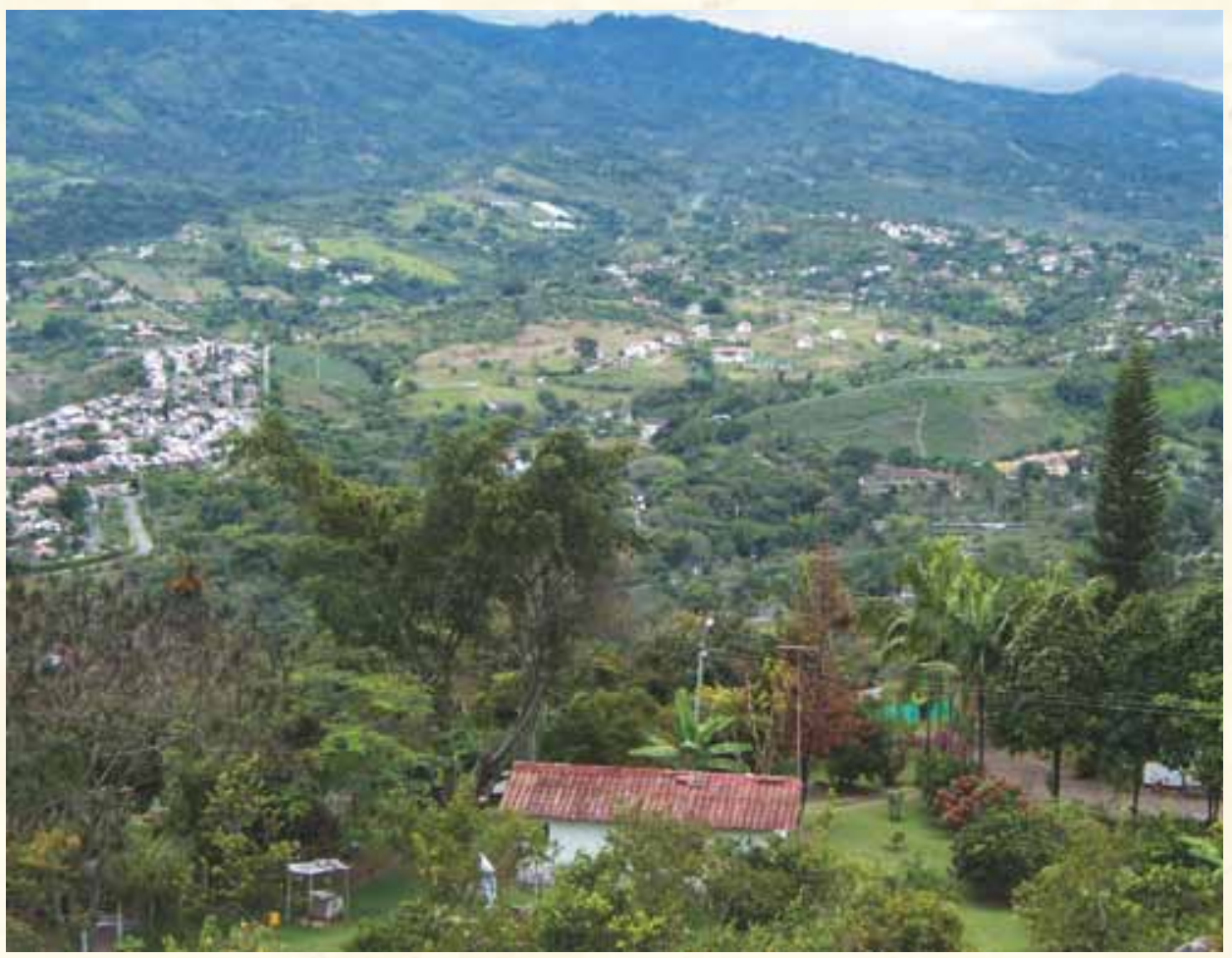

\begin{abstract}
The location of the town of Silvania in Cundinamarca has contributed to development of a second residence tourism phenomenon, been part of Bogota's expansion dynamic where the periphery urbanization process has result in capitalism idea of a new sub urbanization event. This expansion process has caused the decrease of environmental qualities present in the area before and also has changed the second residence tourism concept to a straightforward developers' opportunity autonomous of the legal established governmental planning process. To illustrate the idea has been developed: Historic events, conceptual elements, and planning process referred to Silvania.
\end{abstract}

\title{
KEY WORDS
}

Second Residence, Sub-urbanization 


\section{INTRODUCCIÓN}

Las ventajas comparativas del municipio de Silvania representadas en su localización en el piso térmico templado, con el mínimo desplazamiento desde Bogotá (45 min. en carro), el equipamiento recreativo ejemplificado en el club El Bosque, entre otros aspectos, generan con Bogotá una relación de movilidad estacional (fin de semana, vacaciones), que han hecho atractivas las inversiones en finca raíz, particularmente para segunda residencia (SR). Su emplazamiento en el espacio rural cambia las expectativas de ocupación y trabajo tradicional, ante la motivación de procesos especulativos más que productivos y lo que empieza como un proceso de gentrificación de la periferia con fines recreativos y de inversión urbana, termina ante su masificación con una percepción del entorno sin el carácter y calidad ambiental inicial. La representación de la paradoja "el símbolo de la destrucción del turismo por el turismo" (Anrig, 1985).

Expresión crítica del eco-socialismo a las contradicciones del capitalismo frente a su lógica destructiva de las "condiciones de producción"

Este tipo de turismo es uno de los de mayor inclusión en el escenario rural próximo a las ciudades, por la relación costo-beneficio que involucra paisaje y accesibilidad bajo la motivación del imaginario de tranquilidad y libertad en oposición a lo que podría representar lo urbano. El concepto de "naturaleza mercantil"' se hace evidente en esa actividad dentro de la lógica capitalista, que implica el máximo beneficio privado inmobiliario a corto plazo con el consecuente deterioro ambiental que esto supone.

La SR representa parte de la materialización de ese mercado y la construcción del Club Campestre El Bosque en 1975 en ese municipio, se constituyó en el hito temporal y espacial del Turismo de Segunda Residencia (TSR) que vincula a Bogotá. Su definición la resume Hiernaux-Nicolas (2005) así:

el turismo de segundas residencias es aquel por el cual las personas acuden a un destino o una localidad que no es forzosamente turística per se, donde tienen la posesión por compra, renta o préstamo de un inmueble en el cual pernoctan y realizan actividades de ocio y esparcimiento.

\section{ANTECEDENTE HISTÓRICO}

El origen de la SR puede reconocerse desde la diferenciación cultural occidental que se establece entre el urbanismo latino mediterráneo y el anglosajón, por lo que representó históricamente su forma de emplazamiento en el medioevo Europeo. Analiza Dematteis (1997) de manera comparativa que el "suburbano" anglosajón no es de tipo rural, sino una invasión permanente y con baja densidad de los espacios rurales por parte de la ciudad. Lo que contrasta con el "suburbano" latino que es de tipo rural, toda vez que es una relación basada en "segundas residencias" que se entiende como una evasión a los condicionamientos sociales de los centros urbanos medievales. La búsqueda de la libertad reconocida en lo rural.

En esa diferenciación del mundo anglosajón y el mundo latino mediterráneo medieval expresa Dematteis (1997) de manera sintética y metafórica, que la periferia es para el anglosajón "LA CIUDAD JARDÍN" mientras que para el latino Europeo es "EL JARDÍN DE LA CIUDAD”. Así se entiende, entonces, que para el anglosajón la sub-urbanización es una expansión de la ciudad que se extiende en forma de mancha de aceite alimentada con el acceso de las clases medias y obreras en especial desde la revolución industrial. La urbs se dilata junto con la civitas. 
Para el caso latino mediterráneo la sub-urbanización se hace sin expansión de la ciudad, pero su presencia existe aunque de manera camuflada. Así en I 350 Florencia estaba rodeada por seis mil habitáculos ricos y nobles que de juntarse hubieran conformado dos Florencias (Dematteis, 1997). Esto último ejemplifica el origen latino medieval de la SR como forma de alojamiento temporal de patricios o aristócratas. Como latino-americanos es consecuente esperar una tendencia en esa línea como mutación en el presente y lo local.

En el siglo XIX la diferenciación cultural planteada anteriormente cede paso a los efectos sociales de la Revolución Industrial y la Revolución Francesa pues amplía el horizonte de usuarios hacia la burguesía como estrato emergente de la época que tiene el ideal de la casa de campo como expresión de ocio y prestigio. Será la burguesía económica e intelectual la que convierte la tradición aristocrática de la residencia de recreo en un fenómeno con mayor significación espacial (López, 2003).

Esta etapa europea de la SR, tiene en el desarrollo tecnológico representado en los ferrocarriles el motor de dispersión geográfica y en la filosofía de la llustración la motivación que da el valor del descubrimiento de la verdad a través de la naturaleza. Se trata ahora de un turismo burgués que no sólo busca el clima y la belleza del lugar sino, que al igual que la antigua aristocracia, levanta grandes construcciones (López, 2003).

Este proceso burgués de la SR se fortalece además por la imagen de degradación humana y física de las ciudades europeas en época industrial. Charles Dickens en su libro Historia de dos ciudades, es muy gráfico en mostrar esa doble condición:

Las calles, llenas de baches, depósitos de fango y de agua corrompida, carecían de aceras. Los faroles, que a intervalos muy largos pendían de unas cuerdas, derramaban sobre ellas una luz enfermiza que no bastaba a disipar las tinieblas como no disipaban las tinieblas del mar la luz de los faroles colocados en lo alto de las vergas. A decir verdad, París era un mar, y tanto el barco como los que lo tripulaban corrían grave peligro de naufragar. (p.3I, 1984)

\section{ELEMENTOS CONCEPTUALES}

\section{Matices}

Intentar conseguir consenso en la definición y clasificación de SR es complejo ante el gran matizado que se desprende de múltiples localizaciones, implantaciones, y modelos de turismo. Según sea el criterio de análisis se permitirá una definición y una clasificación particular. En la definición de Hiernaux-Nicolas (2005), se precisa por parte del mismo autor dos puntos centrales. El primero y más importante es el hecho de que el turista no utiliza servicios ni estructuras turísticas comerciales para la pernocta, sino que aprovecha una estructura habitacional (casa o departamento) que suele haber comprado o que renta fuera del sistema de alojamiento. Por otra parte, estas estructuras de alojamiento no se encuentran forzosamente en un destino turístico, de tal suerte que no participan de la misma manera de una cierta "vida turística" propia de los destinos usuales.

Cuando la SR están dentro de un proceso y lugar turístico, estas se sitúan como "alojamiento privado"2 para la pernocta y realizar actividades de ocio, en competencia al "alojamiento colectivo" 3 . Se advierte de lo anterior unos criterios de clasificación o matices muy diversos,
2 "El alojamiento privado como la forma de alojamiento turístico que no se ajusta a la definición de establecimiento". El alojamiento turístico privado ofrece en alquiler o gratuitas, un número de plazas determinadas. Cada unidad de alojamiento-habitación, vivienda es independiente y la ocupan turistas, normalmente durante una semana 0 fin de semana, quincena o mes o sus propietarios como segunda residencia o vivienda de vacaciones" (Rodríguez Salmones, 2003).

3 "El alojamiento colectivo se define como el establecimiento de hospedaje que presta servicio de alojamiento a viajero, ofreciendo habitaciones u otro acomodo para pasar la noche, pero este servicio debe contar con un número de plazas superior a un mínimo determinado para colectivos de personas que sobrepasa a una sola unidad familiar y disponer, aunque no tenga fines de lucro, de una administración de tipo comercial común para todas las plazas de un mismo establecimiento" (Rodríguez Salmones, 2003) 
que corresponderán a los intereses de análisis que se tengan. Estos corresponden según López (1993) principalmente a:

I. La frecuencia temporal: rasgo diferencial de la SR frente a la principal, es uno de los elementos más utilizados. Habitualmente se diferencian las SR utilizadas durante estancias breves pero frecuentes de las esporádicas y prolongadas.

2. La localización: por la situación geográfica generalmente se diferencian tres tipos de SR: las de periferia de las ciudades o centros urbanos, las ubicadas en áreas rurales o en el campo y las localizadas en la montaña o en franjas litorales.

3. La finalidad de la vivienda: en la que sobresale los usos turístico-recreativos y las que se destinan a usos laboral, académico, agrícola o de otro tipo.

4. La implantación territorial: que diferencia entre dispersas y agrupadas. También según sea la relación con las poblaciones donde se asientan, se distingue la SR que se implanta en el núcleo de aquellas ubicadas en edificaciones anejas sin relación con los centros existentes.

5. Morfología, el origen de los ocupantes, la disponibilidad de servicios y el régimen de tenencia: son otros criterios de clasificación.

Como se observa, reviste gran complejidad elaborar una clasificación de SR, ya que se acomoda a situaciones diferentes entre sí. Desde el trailer o casa rodante típicas de los norteamericanos, hasta las haciendas recicladas (de producción decadente) con fines turísticos de países latinoamericanos, podrían identificarse un sin número de tópicos y variedades.

EI TSR en un ambiente rural, en un contexto peri-urbano $y$, desde una perspectiva local hace parte de esta reflexión con énfasis en el cuarto aspecto referenciado por López, toda vez que se trata de ver la dinámica de ocupación en torno a la reflexión de su masificación.

\section{Modelos de localización}

Corresponden según Aldskogius (1969), tanto al emplazamiento (forma del terreno, superficies de agua, vegetación, usos de la tierra y provisión de servicios) como a la situación (carreteras desde el centro de demanda al hinterland rural, transporte público) que se dé, que favorece siempre la opción más cercana. Se reconoce por parte del mismo autor que puede haber particularidades que alteren la visión anterior, como motivaciones sentimentales producto de arraigo familiar o religioso, aunque existe consenso en que paisaje natural y cultural, clima, accesibilidad y dotación de servicios son los factores que más influyen en el desarrollo del TSR.

En el primer factor históricamente la costa y las montañas al igual que características sociales y culturales opuestas a la urbana son atractivas para satisfacer en parte el sentimiento de biofilia ${ }^{4}$. El clima como oferta ambiental se hace importante en términos sanitarios como beneficio preventivo y curativo de una amplia gama de enfermedades cardiacas, respiratorias y dermatológicas entre otras. Accesibilidad y dotación de servicios hacen parte de los factores señalados como "estructurales" o de base.

Los comportamientos locacionales de SR están ligados a condiciones funcionales de la dinámica urbana, ampliamente modelada por la geografía y asociada a procesos metropolitanos, sin embargo, son muy pocos los modelos que expliquen la particularidad de este 
tipo de asentamientos. López (2003) identifica dos tendencias que recogen esa inquietud en modelos dinámicos y modelos explicativos.

En la primera tendencia se reconoce a Lundgren (1974) basado en investigaciones sobre la SR en Canadá. Él propone un modelo con tres fases que explican las transformaciones espaciales entre un centro urbano emisor y las áreas de vivienda secundarias.

"La primera fase se inicia con el surgimiento de un pequeño núcleo de residencias temporales en torno a un centro urbano, generalmente en los parajes de mayor atractivo. La segunda, a medida que crece el área urbana, se expande la demanda de viviendas temporales. En la tercera fase, el área original es absorbida por la expansión metropolitana y acaba por formar parte de la propia ciudad. Las residencias secundarias pasan a ser principales, y mientras tanto, se ha generado un nuevo núcleo de residencias temporales, más alejado".

La crítica para este modelo se centra en no reconocer la importancia del precio del suelo y los casos de segundas residencias lejanas del domicilio habitual. Para la segunda tendencia, es decir el modelo explicativo que contempla la organización del turismo en general incluida la segunda residencia, se tiene en cuenta la distribución desigual del territorio en función de la distancia, la accesibilidad, la valoración paisajística y el precio del suelo. Resume López con ese criterio el modelo de Claval (1980) así:

"en el se distinguen tres áreas: la primera, situada a una distancia media de I50 $\mathrm{Km}$ respecto al centro emisor (el lugar de la residencia habitual) se caracteriza por el uso prácticamente exclusivo de turismo de residencias secundarias para fines de semana y vacaciones. En la segunda área situada entre los 150 y $1.500 \mathrm{~km}$., los factores paisajísticos (playa, montaña, u otros.) juegan un papel muy importante. En esta área la residencia secundaria coexiste con otros alojamientos turísticos (hoteles, apartamentos, camping). Finalmente, según Claval, a más de $1.500 \mathrm{~km}$. del centro emisor las residencias secundarias son prácticamente inexistentes."

Como corolario de estos modelos teóricos, la SR está altamente vinculada a la dinámica de crecimiento urbano y el turismo. Se trata del paso del concepto periurbano que controla estos usos, para luego dar cabida al concepto suburbano que los anula en forma de primera residencia, dando origen a nuevos espacios con SR, que infiere el carácter especulativo de la actividad.

\section{ORDENAMIENTO TERRITORIAL}

\section{Masificación y efectos territoriales}

Después de la II Guerra Mundial, la situación de número de SR cambia notablemente para los países desarrollados, convirtiéndose en una actividad de masas de la que disfruta gran parte de la sociedad. Para Clout (1976) tal explosión en número se ha producido a causa de cuatro factores:

I. La elevación del nivel de vida, la cual ha ido acompañada de altas tasas de crecimiento económico en Europa y América del Norte.

2. La generalización creciente de las vacaciones pagadas. 
3. La continua expansión de los medios de transporte para las masas, en especial el automóvil.

4. La organización de equipamientos recreativos a gran escala.

También, a su vez, la progresiva urbanización y el modo en que se ha llevado a cabo genera necesidades de evasión del sistema de vida urbano. En ese sentido se reconoce como principal la concentración de la población en las grandes ciudades. La proporción de los usuarios de residencias secundarias es mayor cuanto más poblada y densa es la aglomeración urbana en la que habitan (Valcárcel, 1975). De ello se desprende que, posiblemente, un desarrollo más horizontal de las ciudades hubiera comportado una reducción de la residencia secundaria.

El campo como factor de masificación de SR también contribuye a su explicación, dadas las dinámicas simultáneas que tiene con la ciudad. El desarrollo de la residencia secundaria en el campo ha sido posible gracias al éxodo rural, que ha liberado viviendas principales para otros usos y al mantenimiento de una cierta población rural (Jung, 1972). Se percibe para el futuro una aceleración aún mayor de esa migración ante la inviabilidad económica del minifundio por políticas aperturistas de mercado. Así, el espacio quedaría abierto aún más para la SR, pero paradójicamente sin el imaginario atractivo que constituye el campo no como una industria de alimentos, sino como una forma de vida o cultura diferente a la urbana.

Ante la masificación de SR en los lugares asociados al turismo, pueden darse situaciones de hacinamiento y baja calidad ambiental, que no constituyen mayor contraste con el ambiente de residencia habitual. Ese contrasentido lo expresa Gili (2003) con un ejemplo que ilustra esa situación en el caso de propietarios de SR de una urbanización en Taül (Catalunya), que se manifestaron legalmente en contra de otro complejo de viviendas próximo, al considerar que ellos habían pagado por un entorno y una calidad medioambiental que quedaban difuminados con la construcción de otro condominio.

Los efectos de la sub-urbanización estacional como llamaría el inglés Clout (1976), el TSR tiene ventajas y desventajas en su relación con el medio rural. Se reconoce que ante usos de la tierra obsoletos, este puede ser una alternativa racional para el progreso económico de regiones rurales atrasadas. Oportunidades de vender terrenos y construcciones a precios urbanos, el recaudo de impuestos adicionales para las autoridades rurales y el incremento de negocios de uso complementario recreativo y de construcción.

En consonancia con la ventaja anotada, Carrizosa (2005) ve en el TSR para el caso colombiano, una alternativa de generar sostenibilidad local ${ }^{5}$ por vía de las transferencias de la ciudad hacia el campo. Así lo expresa:

5 Frente a la visión de sostenibilidad global por parte de los ecólogos sistémicos y macro-economistas, la sostenibilidad de sitios específicos es el objeto de estudio de la ecología de paisajes, la economía ecológica, la antropología cultural, la sociología ambiental y el ambientalismo integralista (Carrizosa,2005). 
tando. En ocasiones, estos nuevos pobladores del campo lo hacen en buenas condiciones de integración social con sus vecinos campesinos, participan en actividades comunales, transfieren tecnología y suministran empleo que podría ser caracterizado como improductivo en términos económicos. No es entonces utópico pensar que estas actividades voluntarias, con las que se reconoce la multiplicidad de valores inherentes a lo rural y se dignifica el trabajo campesino, puedan ser el ejemplo o la semilla para constituir un proceso significativo de reconciliación política y social”. (p. 67,2005$)$

En las desventajas reconoce Clout (1976), que las condiciones de tráfico rodado rural pueden ser peligrosas, que la organización de explotaciones agrícolas puede ser obstaculizado, que el medio ambiente visual puede ser deteriorado, que se disminuyen las posibilidades de usos locales ante los nuevos precios del suelo que ambientan la especulación.

Otras visiones atienden aspectos más estructurales y generales del turismo, que entienden que este nace por unos recursos $y$ un patrimonio natural y cultural que atrae a la demanda; $y$ exige unas infraestructuras, bienes y servicios que implican el consumo de recursos escasos (suelo, agua y energía, entre otros.) y genera emisiones, residuos y vertidos, que afectan los recursos que le sirven de atractivo. Advierte Serrano (2002), en ese sentido que se vislumbra un deterioro del patrimonio que invalida un turismo de calidad y favorece el de cantidad.

Planteada de esa manera la sostenibilidad del TSR, se entiende que es producto de aspectos más allá de la dinámica urbana y que se debe reconocer en ella la instancia política e ideológica como generadora de desequilibrios. Para el caso de un país altamente turístico como España se aprecia en ese sentido por parte de Serrano ( 2002) que:

"Como apreciamos, existen diferencias entre una opción neoliberal, que en el fondo lo que defiende es el máximo beneficio privado inmobiliario a corto plazo como criterio director de la actuación territorial, y la búsqueda de una mayor sostenibilidad del desarrollo, que exige una ordenación del territorio, ambiental y urbana, que posibiliten la supremacía de los intereses generales a largo plazo sobre los particulares a corto plazo; aunque dichas ordenaciones son insuficientes si no se consigue una "cultura ambiental" que obligue a aplicar y hacer cumplir los mecanismos precisos para conseguir ese desarrollo y turismos más sostenibles en España.” (p. 2, 2002 )

Queda expuesta de alguna manera en esta idea de sostenibilidad, la contravía o el contrasentido que plantearon los usuarios de SR en Taül a sus vendedores. Se vende paisaje y suelo a corto plazo, mientras que las expectativas del que los compra son a largo plazo y se olvida el principio de prevalencia del interés general sobre el particular.

La problemática principal en la idea de ordenamiento territorial que se deriva de la residencia secundaria, es el gran consumo de suelo para su implantación con densidades bajas y para su sostenimiento representado en obras indirectas como canalizaciones de agua, redes eléctricas, vías de acceso, reservas de "paisaje", y otros. Este aspecto debe generar interés más allá del alcance local particular de esta actividad, para observarse en función de la dinámica de crecimiento de la ciudad madre, o ámbito metropolitano cuando sea el caso.

La conurbación expresada en los modelos expuestos anteriormente, materializan en el tiempo esa dinámica urbana que obliga el traslado de segundas residencias a un "anillo" posterior. Se trata entonces de un proceso inicial de extensión de la ciudad en el campo 
para posteriormente preparar su crecimiento. Esta secuencia alimenta el carácter especulativo que se ha venido mencionando como una motivación adicional a la del ocio y la recreación y debe ser un elemento principal de control en el ordenamiento del territorio.

La planificación de la SR o "suburbanización estacional”, tiende a soluciones de concentración estratégica en forma de urbanizaciones cerradas y controladas con el criterio según Clout (1976) de que:

"La concentración significaría que los planes de ampliación de fincas y de repoblación forestal no se verían obstaculizados, y el paisaje rural no se vería 'minado' por las viviendas secundarias dispersas. Sólo se sacrificarían las áreas inmediatas a las urbanizaciones." (p. I25)

Es claro que prima el criterio de optimización de recursos particulares y el supuesto bajo impacto en el espacio rural, sin embargo, este último en nuestro medio resulta altamente segregador de dos realidades sociales distantes. Es un intento de aislamiento social bajo la forma de "fortalezas militares" con nombres y cerramientos verdes en algunos casos para disfrazar su impacto.

Más allá de la forma concentrada o dispersa es importante evaluar los costos de mantenimiento y conservación que implican estos asentamientos con tendencia a constituirse tarde que temprano en primera residencia. Las zonificaciones de usos y tratamientos en los POT, conlleva considerar el ámbito de la producción pero también el del consumo que se implica o huella ecológica. Es de cortas miras cualquier planteamiento tendente a continuar con un proceso de crecimiento indefinido de este sector, aunque a nadie se oculta las complejas y delicadas tareas que debe enfrentarse toda política de ordenación territorial (Merlín, 2002).

La complejidad está en aspectos estructurales como se citaba anteriormente, en el hecho de enfrentar intereses económicos particulares a corto plazo con los intereses generales a largo plazo en búsqueda de una sostenibilidad del tema, pero también está en aspectos técnicos de planificar algo que en ocasiones constituye un paso previo a futuros desarrollos urbanos de carácter permanente.

Consecuentemente, la ordenación de la SR debe plantearse en el contexto de una visión territorial amplia (ciudad-región) y en correspondencia de los procesos sociales que se den desde otros escenarios. Esta no debe excluir tampoco, la visión local que los municipios tengan de su propio proyecto de futuro.

\section{Silvania y su Plan Básico de Ordenamiento Territorial}

El municipio de Silvania reúne ventajas comparativas representadas en los niveles de emplazamiento y de situación como clasifica Aldskogius los factores de localización que posibilitan el desarrollo del TSR de una manera masiva. Como reconocimiento de lo anterior, el actual ${ }^{6}$ Plan Básico de Ordenamiento Territorial (PBOT) del municipio destina para ello una gran área ${ }^{7}$ con clasificación suburbana ${ }^{8}$ que posibilita la convivencia de las actividades residenciales y agropecuarias entre otras, bajo la regulación de los diferentes tratamientos normativos. 
EI TSR hace parte de la vida del municipio, a tal punto que éste se reconoce amplia y genéricamente como la "zona de condominios". La construcción en 1967 del tramo Chusacá-Silvania-Fusagasugá de la vía panamericana que reemplazó el carácter principal de Sibaté-Aguadita-Fusagasugá hasta ese momento, significó para el municipio de Silvania algo así como el fortalecimiento de su columna vertebral, dado que ésta es meridional al área del municipio y a su relación funcional con Bogotá. Este se tradujo en mayor equipamiento urbano entre lo que sobresale destacar, la construcción del Club Campestre El Bosque (Foto I) que se beneficia de esa nueva condición de accesibilidad y valorización que sumada a las condiciones ambientales expuestas, proporcionan un ambiente económico para la implementación del turismo ${ }^{9}$

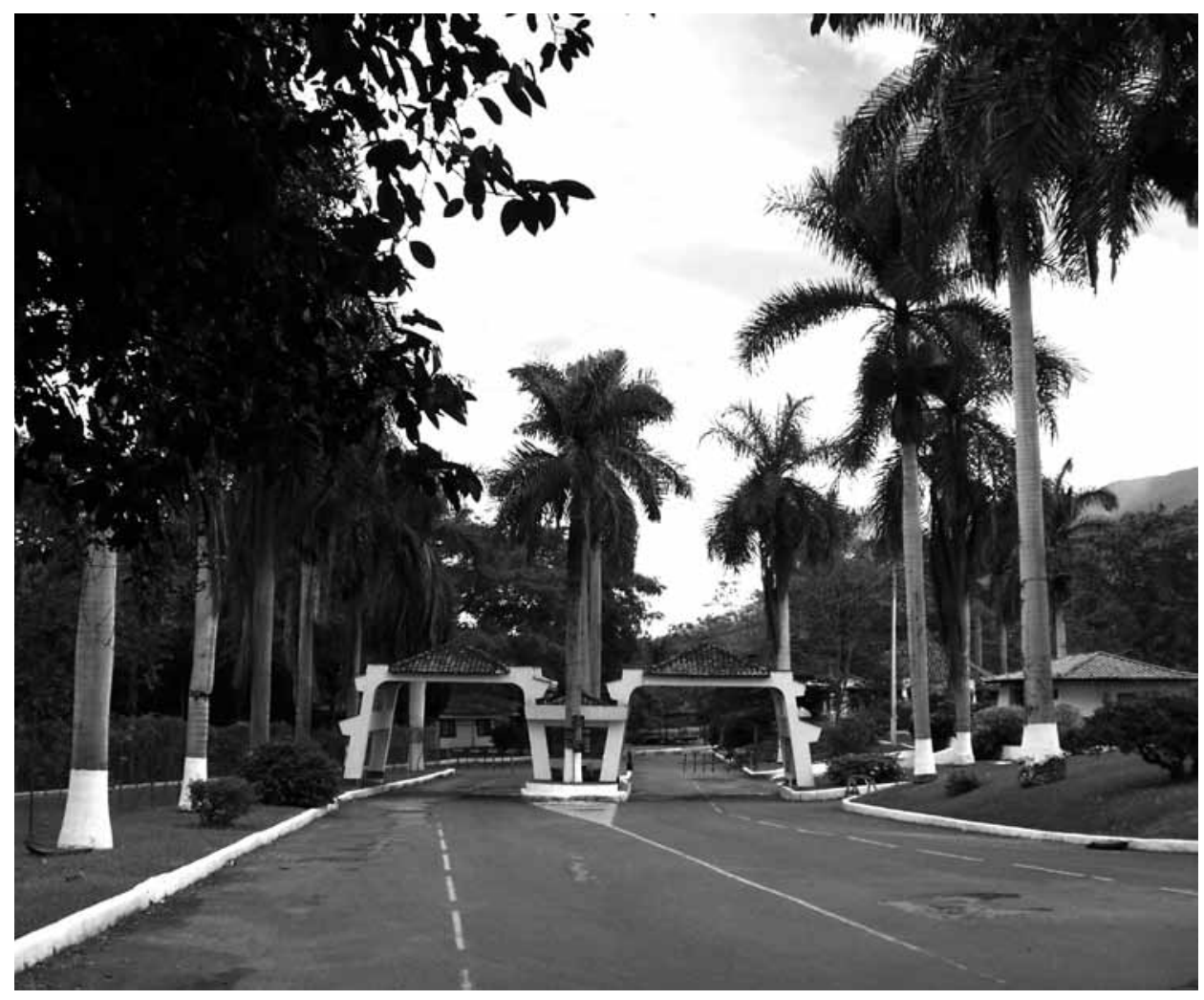

9 Se establece concordancia con el cuarto factor que establece Clout (1976) para explicar el origen de la segunda residencia cual es la organización de equipamientos recreativos a gran escala, esto a su vez, fue potenciado por el segundo factor que se reseña como la expansión de los medios de transporte para las masas.

10 ARTÍCULO 65. RESIDENCIAL RE CREACIONAL: Comprende las actividades con miras al descanso y esparcimiento en espacios y áreas en e suelo suburbano (Sector condominios) desarrollados a partir de las agrupaciones o conjuntos de baja densidad, el índice de ocupación máximo es de $30 \%$ del predio, y el restante $70 \%$ es área a reforestar con especies nativas. Se entiende por ocupación máxima, e área de construcción tanto cubierta como descubierta (áreas complementarias, vías). El desarrollo de esta actividad socioeconómica se podrá realizar siempre y cuando se garantice el autoabastecimiento de servicios públicos.

II ARTÍCULO 66. RESIDENCIAL CAMPESTRE: Comprende las actividades con miras al descanso y esparcimiento acompañada de pequeños desarrollos agrícolas no formales, en espacios y áreas en el suelo suburbano (sector condominios); el globo de terreno se mantendrá como unidad indivisible, en donde los predios no podrán fraccionarse por debajo de una hectárea, y su índice de ocupación máximo será del 15\%

Foto I. Acceso al Club Campestre el Bosque

Dado lo anterior y al cotejar la cartografía predial y de actividades de comienzos de la década de los ochenta con la actual, en el área que actualmente tiene zonificación suburbana dentro del municipio, se evidencia que la construcción del club campestre El Bosque en 1975 generó un incentivo para el desarrollo del TSR. Al materializar ese hecho inicialmente, la urbanización Pueblito El Bosque proyectada en 1988 establece una relación complementaria de uso con el club sustentada en la contigüidad espacial.

Esta primera manifestación masiva de SR bajo la forma Residencial Recreacional ${ }^{10} \circ$ lo que es igual, vivienda agrupada en conjunto cerrado, está acompañada aunque en menor cuantía de la forma Residencial Campestre " que es polarizada por la vía Silvania-Tibacuy. Su implantación permite la actividad agropecuaria dentro de sus predios, lo cual la separa del concepto de chalet que se asocia generalmente sin esta actividad productiva (Ver Foto 2 ). 


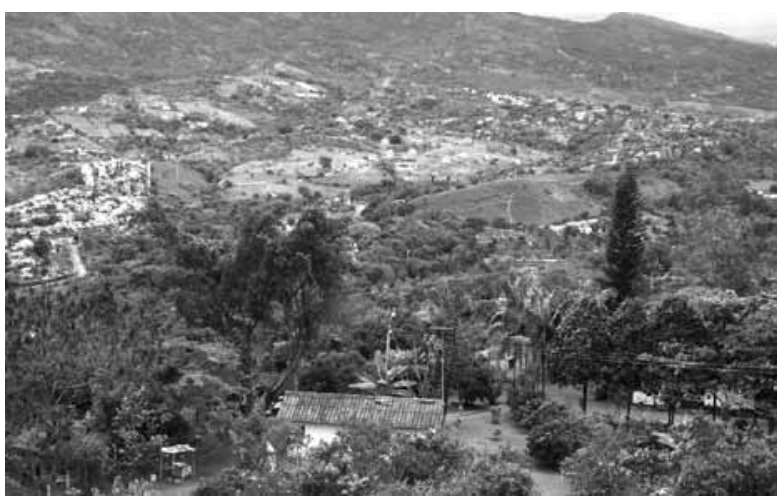

${ }^{12}$ Foto 2. El contraste Residencial Campestre en primer plano con el Residencial Recreativo al fondo.

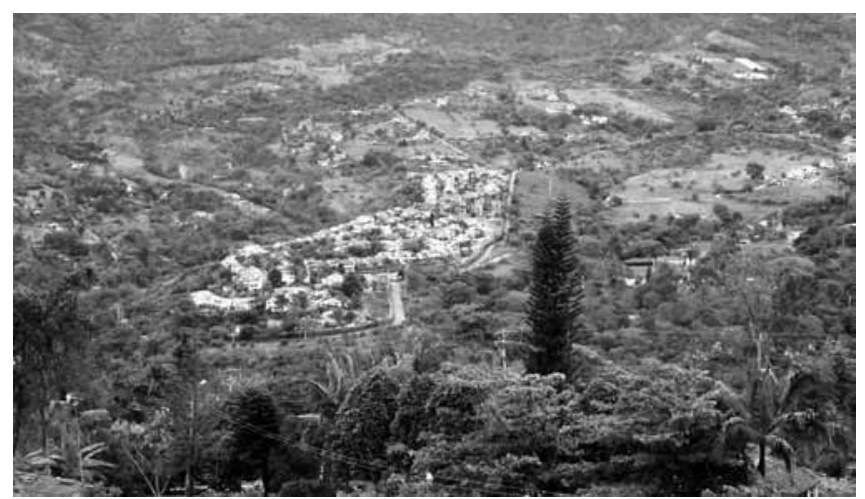

Foto 3. Residencial Recreativo al fondo con dos intensidades, a la izquierda lo denso del Pueblito el Bosque y a la derecha una menor densidad en otros condominios. El telón de fondo lo constituye la cuchilla topográfica Peñas Blancas
12 I.O. $=0.65$ Aprox.

13 I.O. $=0.15$ promedio Aprox.

14 I.O. $=0.60$ Aprox.
El carácter agrupado del Pueblito El Bosque se ve replicado durante la década de los 90 de manera masiva, aunque se cambia la estandarización constructiva densa ${ }^{13}$ por un proceso de construcción progresiva con menor densidad ${ }^{14}$ donde puede quedar a criterio de cada comprador la adquisición del predio con o sin la vivienda terminada, pero se restringen las condiciones de estilo arquitectónico que son consecuentes a la forma de copropiedad en la tenencia del predio (Ver Cuadro I y Foto 3 ).

Cuadro I Relación de condominios principales observados en el área suburbana de Silvania

\begin{tabular}{|l|c|c|c|}
\hline $\begin{array}{c}\text { NOMBRE } \\
\text { CONDOMINIO }\end{array}$ & $\begin{array}{c}\text { ÁREA } \\
\text { APROXIMADA Ha. }\end{array}$ & $\begin{array}{c}\text { ÍNDICE DE } \\
\text { OCUPACIÓN }^{\prime}\end{array}$ & $\begin{array}{c}\text { AÑO } \\
\text { PROYECTO }^{2}\end{array}$ \\
\hline Pueblito El Bosque & 80.6 & 0.49 & 1988 \\
\hline Los Alpes & 13.1 & 0.15 & 1989 \\
\hline Sauzalito & 13.5 & 0.18 & 1990 \\
\hline Loma Linda & 12.4 & 0.11 & 1990 \\
\hline Quebraditas & 15.1 & 0.14 & 1990 \\
\hline El Refugio & 32.3 & 0.17 & 1990 \\
\hline Granjas del Bosque I & 35.5 & 0.05 & 1990 \\
\hline Mirador de Tierra Linda & 5.2 & 0.30 & 1993 \\
\hline Rincón del Bosque & 13.0 & 0.10 & 1994 \\
\hline El Pedregal & 19.6 & 0.09 & 1994 \\
\hline Hacienda El Bosque & 9.3 & 0.60 & 1997 \\
\hline
\end{tabular}

Fuente: Elaboración propia a partir de planimetría

La excepción a la generalización anterior durante la década de los 90 , la constituye el condominio Hacienda el Bosque, que como próximo al Club y habiéndose dado cierta consolidación del tema inmobiliario en la zona hasta ese momento, desarrolla en 1997 como proyecto un conjunto urbanístico de gran densidad ${ }^{14}$ que hace evidenciar el efecto especulativo que el TSR genera en el espacio rural (Foto 3). En otras palabras, se trató en los casos nombrados de hacer valedera la masificación de segunda residencia como una forma de crecimiento económico atractiva en esos términos para el municipio, que sin embargo, pueden propiciar efectos nocivos en el ambiente, mayores a sus beneficios. Manifestaría en ese caso el eco-socialista catalán Juan Martínez Alier (1992) que: 
“la idea de que el crecimiento económico es 'bueno' para el ambiente no puede ser aceptada (...) Un crecimiento económico generalizado puede agravar, en vez de disminuir, la degradación ambiental, aunque la misma riqueza permita destinar más recursos a proteger el ambiente contra los efectos causados por ella misma” (...).

Se establece de la secuencia anterior, que el municipio de Silvania completó a partir del desarrollo de la vía Panamericana las condiciones potenciales de oferta turística que desde el punto de vista ambiental biofísicas ya estaban dadas en el sur del municipio por las características derivadas del cambio altitudinal contrastado con Bogotá 15 . Consecuente a lo anterior, la implementación de polos de desarrollo como el Club Campestre El Bosque, que aunque de origen privado empieza a marcar diferencia en la oferta turística respecto de otros municipios, pues establece un PRIMER MOMENTO en la dinámica de ocupación del territorio en el tema turístico.

Se verifica también, que el desarrollo del club sin capacidad de instalación para la pernocta, genera consecuentemente por iniciativa particular, vivienda secundaria estandarizada y organizada por sistema de copropiedad como estrategia para obtener máximos y rápidos rendimientos de instalación e inversión. Se da entonces, un SEGUNDO MOMENTO de cambio en el ambiente rural con la construcción (en tres etapas próximas) de la urbanización Pueblito El Bosque a partir de un plan urbanístico denso ${ }^{16}$ que hace correlato con su nombre.

Contrariamente a lo esperado con excepción del condominio Hacienda el Bosque, la tendencia gradual positiva de densidad en otros condominios no se da totalmente ante el elevado índice de ocupación que impuso inicialmente el Pueblito El Bosque al llenar rápidamente las expectativas de alojamiento de socios del club y, en general, de sus visitantes. Se aprecia entonces, un TERCER MOMENTO con un proceso de menor densidad aunque con las mismas condiciones de la actividad Residencial Recreacional, en detrimento de la actividad Residencial Campestre de iniciativa particular e individual por efecto probablemente de las economías de escala asociada a la primera ${ }^{17}$.

El comienzo de la descentralización administrativa municipal en la década de los 90 y el vacío normativo ${ }^{18}$ del concepto suburba no en esa época para el municipio y aún para otras instancias, patrocino visiones y acciones "políticas" 19 particulares en la regulación de densidades de ocupación del espacio rural, que se formalizaron a través de licencias de construcción avaladas en los diferentes consejos municipales.

La situación planteada y el avanzado proceso metropolitano ${ }^{20}$ de muchas ciudades colombianas, generaron posiblemente como respuesta, la implementación de los POT municipales que funcionan bajo los principios de concurrencia, complementariedad, y subsidiaridad con otras instancias territoriales. Esto implica un CUARTO MOMENTO potencial de ocupación y cambio rural en el municipio con una regulación de ocupación supeditada a la capacidad de carga de la cuenca del mismo en sus posibilidades hídricas de captación y evacuación especialmente.

El carácter apenas potencial de este último momento asociado al PBOT se hace comprensible toda vez que el desarrollo progresivo de condominios de la década pasada capta la demanda presente que se tiene de viviendas secundarias. Se puede inferir al ver la ocupación actual del área suburbana, que la regulación anotada llega como respuesta a un hecho ya consumado (en unos casos acorde a lo dispuesto en el PBOT) que hará prevalecer los derechos adquiridos con anterioridad, pues deja como letra muerta parcialmente, los
15 Bogotá $2600 \mathrm{msnm}$ y área suburbana de Silvania $1600 \mathrm{msnm}$ promedio.

16 I.O. $=0.49$ Aprox.

17 Resulta más ventajoso desde el punto de vista económico comprar casas en pie y de construcción estandarizada, que recurrir a emprender de manera particular la ejecución de la vivienda.

18 La Ley 9 de 1989 no se asumía, sólo desde la Ley 388 de 1997 se empezaron a armonizar sus disposiciones en sintonía con la nueva constitución política.

19 Se dieron dos condiciones para favorecer la acción clientelista.

20 Tasas de crecimiento poblacional mayor en la periferia que en el centro. 
21 En la idea de Dematteis la diferenciación drástica campo y ciudad genera el concepto de peri-urbanización (jardín de la ciudad) diferente a sub-urbanización (ciudad jardín) objetivos trazados para el ideal suburbano que tiene el municipio en consonancia al hecho metropolitano de Bogotá.

\section{CONCLUSIONES Y RECOMENDACIONES}

La cultura latina espacializó ese aspecto desde la época medieval en el contraste entre campo y ciudad ${ }^{21}$, sin embargo, actualmente esa diferenciación drástica cede paso a procesos metropolitanos que apuntan hoy como tendencia a que no exista tal distinción. Se está, entonces, teóricamente ante la finalización de lo rural como un escenario de escape o disipación para dar paso a escenarios híbridos o suburbanos sin gradientes axiológicos.

En ese escenario la SR en el hinterlad rural perderá vigencia ante la posibilidad de ser alojamiento permanente por la influencia que la telemática y la globalización tienen en la dispersión de la ciudad. De tal suerte el proceso vivido en Silvania con este tema durante los últimos 30 años, recoge esa transformación a la par de las particularidades locales que conforman la mutación del proceso.

El tránsito fordismo - posfordismo como una expresión teórica de escala macro, también tiene reconocimiento en lo local en diferentes temáticas. En Silvania el TSR es una pequeña muestra de ese tránsito espacial e imaginario que tiene varias manifestaciones en esos sentidos. El tránsito de la finca al condominio, del bosque al club, entre otros, insinúa ese proceso que se resume a continuación.

Las condiciones ambientales y estructurales o como expresa Aldskogius (1969) de emplazamiento y situación, de la parte sur de Silvania (actual área suburbana), constituyeron un escenario ideal para la proyección turística del municipio, en función de Bogotá como centro de consumo principal de este tipo de servicio. La primera materialización de tal situación se dio con la construcción del Club Recreativo El Bosque, que se constituyó en el hito funcional de la actividad, que operó a su vez, como factor dinamizador de actividades complementarias entre las que se cuenta la segunda residencia como forma de alojamiento.

La implantación del Club el Bosque en el lugar generó de manera gradual el cambio en la distribución y cualidades de la segunda residencia, que primero manifestó un patrón atomizado de baja densidad en lo que hoy se denomina el uso residencial campestre que se combina con actividades agropecuarias de baja producción. La transformación a finales de los años ochenta empieza a darse en dirección opuesta, es decir, bajo un patrón concentrado de alta densidad en el que predominan las actividades de ocio, dando origen al uso residencial recreativo.

La acción principal del PBOT se centra en el control de densidad para hacerla consecuente ante todo con la capacidad de carga de la cuenca hidrográfica en el tema de suministro y vertimientos de aguas. También se hace explícita la reforestación con especies nativas en áreas libres (70\%) como medida de mitigación ambiental. Se opera de esta forma un criterio cuantitativo importante en el PBOT, pero por sí solo resulta insuficiente en la intención de planificar el lugar.

Temas cualitativos que contrastan el imaginario campo y ciudad, como la estandarización del paisaje, la dualización social, las formas de implantación, y sobre todo la dinámica de transformación de segunda a primera residencia entre otros, no son valorados en la normativa de ocupación rural del Plan de Ordenamiento Territorial. 


\section{BIBLIOGRAFÍA}

BORJA, JORDI. Revolución y contrarrevolución en la ciudad global. Revista Bibliográfica de geografía y ciencias sociales. Vol. 10, 578, 2005

CORTÉS, LUIS. La cuestión residencial. Bases para una sociología del habitar. Madrid: Editorial fundamentos, 1955

CLAVAL, PAUL. Geografía económica, Vilassar de Mar, Oikos-Tau, 1980

CLOUT, H. D. Geografía Rural, Vilassar de Mar, Oikos-Tau, 1976

DEMATTEIS, GIUSEPPE. Suburbanización y Periurbanización. Ciudades anglosajonas y ciudades latinas. Barcelona, Centro de Cultura Contemporánea de Barcelona, 1997

ESCORCIA, JOSÉ. "La formación de las clases sociales en el periodo de la Independencia” en Germán Colmenares, Zamira Díaz, José Escorcia y FRANCISCO GILI, MERCÉ. Las viviendas de segunda residencia ¿Ocio o negocio? Scripta Nova. Revista electrónica de geografía y ciencias sociales. Barcelona 2003: http:// www.ub.es/geocrit/sn/sn-I 46(052).htm

HIERNAUX-NICOLÁS, DANIEL. La promoción inmobiliaria y el turismo residencial: El caso mexicano. Scripta Nova. Revista electrónica de geografía y ciencias sociales. Barcelona 2005: http:// www.ub.es/geocrit/sn/sn-194(05).htm

KEMENY, JIM. Housing and social Theory. Londres: Routledge, 1992

LÓPEZ, JULIÁN. La residencia secundaria en España: estudio territorial de su uso y tenencia. Tesis Doctoral Universidad Autónoma de Barcelona 2003

MATTOS, CARLOS. 2003. Transformaciones de la ciudades latinoamericanas. ¿impactos de la globalización?. Eure (Santiago), 2003

MONCLÚS, JAVIER. La Ciudad Dispersa. Suburbanización y nuevas periferias. Perspectivas geográfico-urbanísticas. Barcelona: Centro de Cultura Contemporánea de Barcelona, 1998

MORRIS, A.E.J. Historia de la forma urbana desde sus orígenes hasta la revolución industrial. Barcelona, Gustavo Gili, 1984

MUMFORD, LEWIS. The City in History. San Diego, Harcourt Brace Javanovich Publishers, 1961

ORTEGA VARCÁRCEL, J. Residencias secundarias y espacio de ocio en España. Valladolid, Departamento de Geografía, Universidad de Valladolid, 1975

PINO, J. "Aproximación sociológica a la vivienda secundaria litoral”. Scripta Nova. Revista electrónica de geografía y ciencias sociales. Barcelona:Universidad de Barcelona, I de agosto de 2003, vol. VII, núm. I46(026). http:// www.ub.es/geocrit/sn/sn-I 46(026).htm

RENARD, JEAN. Les mutations des campagnes: Paisajes et structures agraires dans le monde, Collection U. París Armand Colin, 2002

RUEDA, S. La ciudad compacta y diversa frente a la conurbación difusa. En: Biblioteca virtual en internet, Ciudades para un mundo sostenible, 1997. www.habitat.aq.upm.es/ cs/p2/a009.html

SERRANO, JOSÉ. Las viviendas de segunda residencia en la sociedad del "bienestar". EI caso de un país turístico: España. Cuadernos de Turismo. Murcia 2003

SAVELLI, A. Sociología del Turismo. Milano, Franco Angeli. 1989 